\title{
PROTOCOLO DE PREPARO DA CRIANÇA PRÉ-ESCOLAR PARA PUNÇÃO VENOSA, COM UTILIZAÇÃO DO BRINQUEDO TERAPÊUTICO*
}

\author{
Maria do Rosário Martins** \\ Circéa Amalia Ribeiro*** \\ Regina Issuzu Hirooka de Borba**** \\ Conceição Vieira da Silva*****
}

Martins MR, Ribeiro CA, Borba RIH, Silva CV. Protocolo de preparo da criança pré-escolar para punção venosa, com utilização do brinquedo terapêutico. Rev Latino-am Enfermagem 2001 março; 9(2): 76-85.

Este trabalho, do tipo exploratório descritivo, consiste na elaboração de um protocolo utilizando brinquedo terapêutico para preparar crianças pré-escolares que seriam submetidas à punção venosa, assim como testá-lo em algumas crianças para verificar sua aplicabilidade e eficiência. As crianças submetidas à sessão do brinquedo, tornaram-se mais cooperativas durante a punção venosa; compreenderam a necessidade e a técnica dos procedimentos; exteriorizaram sentimentos; elaboraram situações familiares e hospitalares, passando a relacionar-se melhor com as outras crianças e com a equipe de enfermagem. Consideramos que este protocolo é factível e útil; sugerimos que integre o plano de assistência de enfermagem a crianças hospitalizadas.

UNITERMOS: jogos e brinquedos, procedimentos clínicos, enfermagem pediátrica

\section{PROTOCOL FOR THE PREPARATION OF PRESCHOOL CHILDREN TO VENOUS PUNCTURE USING THERAPEUTIC PLAY}

This exploratory - descriptive study aims at elaborating a protocol, using therapeutic play, for the preparation of preschool children to venous puncture and also at testing its efficiency and applicability. The children that attended the play session were more cooperative when they were punctured. They understood the need and technical aspects of this clinical procedure; manifested their feelings, elaborated familiar and hospital situations that resulted in a better relationship with the other children and the nursing team. Authors concluded that this protocol is feasible and useful and suggested that it should be incorporated in the nursing care plan to hospitalized children.

KEY WORDS: play and playthings, clinical procedures, pediatric nursing

\section{PROTOCOLO DE PREPARACIÓN DE NIÑOS EN EDAD PREESCOLAR PARA LA PUNCIÓN VENOSA CON UTILIZACIÓN DEL JUGUETE TERAPEUTICO}

Este trabajo de tipo exploratorio descriptivo consiste en la elaboración de un protocolo utilizando el juguete terapéutico para preparar niños preescolares para la punción venosa y su aplicación en algunos niños, con el sentido de verificar su aplicabilidad. Los niños que fueron sometidos a la sesión del juguete, se tornaron más cooperativos durante la punción venosa; comprendieron la necesidad y la

\footnotetext{
* Resumo da Monografia apresentada à Universidade Federal de São Paulo (UNIFESP/EPM), para obtenção do título de Especialista em Enfermagem Pediátrica

** Enfermeira do Hospital Universitário Regional de Maringá-Pr. Especialista em Enfermagem Pediátrica pela UNIFESP

*** Professor Adjunto do Departamento de Enfermagem da UNIFESP. Mestre em Enfermagem Pediátrica. Doutora em Enfermagem pela Escola de Enfermagem da Universidade de São Paulo. Orientadora. Endereço: Rua: Cipriano Barata, 1451 - Ap. 194 - A lpiranga - 04205-001 - São Paulo - São Paulo Brasil

**** Professor Assistente do Departamento de Enfermagem da UNIFESP. Mestre em Enfermagem Pediátrica. Co-Orientadora

***** Professor Adjunto do Departamento de Enfermagem da UNIFESP. Doutora em Enfermagem Materna e Infantil pela UNIFESP
} 
técnica de los procedimientos; exteriorizaron sentimientos; elaboraron situaciones familiares y hospitalarias y empezaron a relacionarse mejor con los otros niños y con el equipo de enfermería. Consideramos que éste protocolo es factible y util; sugerimos que el mismo pase a integrar el plan de atención de enfermería a los niños hospitalizados.

TÉRMINOS CLAVES: juguete terapéutico, punción venosa, enfermería pediatrica

\section{INTRODUÇÃO}

Trabalhando com crianças hospitalizadas e observando seu comportamento durante a internação, presenciamos o trauma que sofrem ao sair do ambiente familiar para outro totalmente desconhecido, enfrentar pessoas estranhas e procedimentos dolorosos, como tomar injeção, fazer curativos e outros. Isto desenvolve na criança uma tal ansiedade que a deixa insegura e medrosa, principalmente quando não é preparada para a hospitalização e o tratamento a ser realizado.

Dentre essas situações estressantes estão os procedimentos intrusivos, como a punção venosa, que muito contribui para aumentar-lhe o medo e a ansiedade, expressos por meio do choro, da raiva e agressões peculiares à criança de três a seis anos de idade. Nesta fase, o trauma é maior porque as crianças não têm estrutura cognitiva para compreender a experiência pela qual passam $^{(1)}$.

A criança nessa faixa etária é muito egocêntrica, acredita que seus pensamentos são poderosos e isto dificulta a aceitação de um procedimento doloroso, como um tratamento necessário, podendo interpretá-lo como um castigo ou punição ${ }^{(2)}$. A criança é também vulnerável às ameaças de lesão corporal.

A principal tarefa do pré-escolar é adquirir o senso de iniciativa e, quando submetido a experiências traumatizantes, surgem os conflitos, porque passa a acreditar que suas ações ou suas imaginações são más, aparecendo o sentimento de culpa ${ }^{(3)}$.

Um estudo realizado por Blom, com crianças de dois a quartoze anos, hospitalizadas, no qual mostra que as causas mais freqüentes de ansiedade são a internação propriamente dita, a operação, as agulhas de injeção e a anestesia ${ }^{(4)}$.

Fala-se sobre a preocupação do pré-escolar com a integridade de seu corpo e o medo de procedimentos intrusivos, quando está doente ou hospitalizado ${ }^{(5)}$. Estes procedimentos podem levá-lo a sentir-se dependente, inseguro e vulnerável; mesmo que o procedimento seja conhecido pode provocar desconfiança tanto na criança quanto nos pais. Um dos eventos mais ameaçadores para a criança é a injeção, porque é percebida como uma invasão extremamente dolorosa em seu corpo, um ato hostil e mutilador ${ }^{(6)}$. No entanto, autores ${ }^{(2,7-13)}$ afirmam que os efeitos da hospitalização e a utilização de procedimentos intrusivos sobre a criança podem ser minimizados por meio de algumas condutas tais como: permitir a permanência dos pais no hospital; evitar o rodízio do pessoal que cuida da criança; prepará-la para a hospitalização, os procedimentos e tratamentos; permitir que ela traga para o hospital seus brinquedos e, ainda, que lhe seja dada oportunidade para brincar.

\section{A importância do brinquedo e sua aplicação no hospital}

Brincar é a atividade mais importante da vida da criança e é crucial para seu desenvolvimento motor, emocional, mental e social. É a forma pela qual ela se comunica com o meio em que vive e expressa ativamente seus sentimentos, ansiedades e frustrações. Por meio do brinquedo, num evento em que é sujeito passivo, transforma-se em investigador e controlador ativo, e adquire o domínio da situação utilizando a brincadeira e a fantasia ${ }^{(14-16)}$.

Brincando a criança expressa de modo simbólico suas fantasias, seus desejos e suas experiências vividas ${ }^{(17)}$. 0 modo como a criança brinca é um indicativo de como está, de como é (18) $^{\text {. }}$

Expressar seus conflitos por meio da brincadeira é a forma mais natural de autoterapia que a criança dispõe ${ }^{(19)}$. Segue dizendo ser possível que o brincar desempenhe muitos outros papéis no seu desenvolvimento, mas que sem dúvida a criança o utiliza para mitigar seus sofrimentos, frustrações e derrotas. Para o autor, brincar é a forma infantil da capacidade humana para lidar com a experiência e dominar a realidade.

Sobre as funções do brinquedo, refere que uma das funções mais importantes é a dramatização de papéis ou de conflitos, que conduz à diminuição da ansiedade por meio da catarse (ou seja, de alívio ou "purificação" do indivíduo ${ }^{(20)} .0$ brinquedo utilizado com essa função, não nos dá somente o diagnóstico do conflito que a criança está vivenciando, mas tem também uma função curativa, pois se constitui numa "'válvula de escape" para seus conflitos. 0 autor afirma, ainda, que o brinquedo é tão importante que constitui a base da psicoterapia infantil, a ludoterapia.

Reforçando as possibilidades de utilização do brinquedo terapêutico, baseia-se também na função catártica e nos princípios da ludoterapia ${ }^{(12)}$, porém com algumas variações ${ }^{(21)}$. Esta autora comenta que o brinquedo terapêutico é um processo de brinquedo não diretivo que dá à criança a liberdade de expressar-se não verbalmente. Descreve ainda a diferença entre ludoterapia e brinquedo terapêutico, conforme segue:

- Ludoterapia: técnica psiquiátrica usada em crianças com distúrbios emocionais, neuróticos ou psicóticos. Cada sessão pode ser 
conduzida por um psiquiatra, psicólogo ou enfermeiro especializado, num ambiente muito bem controlado. Sua meta é promover a compreensão da criança sobre seu próprio comportamento e sentimento. 0 terapeuta deve refletir as expressões verbais e não verbais da criança, bem como interpretá-las para ela. Normalmente as sessões de ludoterapia são de uma hora e podem continuar por vários meses.

- Brinquedo Terapêutico: situação de utilização do brinquedo que pode ser usada pela enfermeira, para qualquer criança. A sessão pode ser realizada em uma sala de brinquedos, no quarto da criança ou em qualquer área conveniente. Sua meta é dar à enfermeira compreensão dos sentimentos e necessidades da criança. Assim, são refletidas à criança somente suas expressões verbais e não se interpretam suas atividades. As sessões devem durar de 15 a 45 minutos e podem ocorrer inclusive no dia da hospitalização da criança.

0 brinquedo terapêutico é também a utilização de uma brincadeira, que simula situações hospitalares, obedecendo os princípios de ludoterapia, porém com um tema mais dirigido, onde a criança receberá explicações sobre os procedimentos a que deve ser submetida, ou descarregará sua tensão após os procedimentos, visualizando as situações e manuseando os instrumentos e suas imitações $^{(22-23)}$.

0 brinquedo terapêutico proporciona à criança hospitalizada a oportunidade de reorganizar a sua vida, seus sentimentos e diminuir a ansiedade, podendo também ser utilizado para ajudá-la a reconhecer seus sentimentos, assimilar novas situações, compreender o que se passa no hospital e esclarecer conceitos errôneos ${ }^{(24)}$. Ressaltam, ainda, que graças ao contato de 24 horas com as crianças, a equipe de enfermagem está em excelente posição para evitar que as crianças ocultem seus sentimentos durante períodos de tensão. Para a criança hospitalizada 0 ato de brincar é importante porque a brincadeira faz com que ela preserve sua saúde emocional ${ }^{(25)}$.

Vários autores ${ }^{(3,6-7,12,21,23-24,26-29)}$ demonstraram em seus trabalhos que a utilização do brinquedo terapêutico é um valioso instrumento no preparo de crianças para procedimentos, pois não só lhes permite extravasar seus sentimentos e compreender melhor a situação, como subsidia a equipe para a compreensão das necessidades da criança. Qualquer enfermeira pode fazer uso do brinquedo $^{(21)}$, sendo considerada um profissional que tem 0 conhecimento necessário e a habilidade de facilitar a brincadeira no hospital ${ }^{(25)}$. Acreditamos, entretanto, que a enfermeira pediatra, pelos seus conhecimentos e sua sensibilidade para identificar os sentimentos e as causas de estresse, seja o profissional mais indicado para utilizá-lo.

Como foi exposto no início deste trabalho, nosso interesse e preocupação com as reações que a criança hospitalizada apresenta quando submetida à punção venosa, levou-nos a procurar uma maneira de auxiliá-la a enfrentar essa situação difícil, tornando-a menos traumatizante.

Tendo conhecimento dos estudos desenvolvidos pelos autores anteriormente citados, e estando de acordo com suas idéias, resolvemos elaborar um protocolo com utilização do brinquedo terapêutico, para preparar crianças na idade pré-escolar que devem ser submetidas à punção venosa, e testá-lo em algumas crianças para verificar sua aplicabilidade e eficiência, bem como propiciar um meio de alívio para as tensões e medos da criança frente à punção venosa. Desta forma, este trabalho tem como objetivos:

1. Propor um modelo de protocolo, com a utilização do brinquedo terapêutico, para o preparo da criança pré-escolar que será submetida à punção venosa.

2. Verificar a aplicabilidade do protocolo elaborado.

3. Propiciar um meio de alívio para as tensões e medos da criança, frente à punção venosa.

\section{METODOLOGIA}

Trata-se de um estudo exploratório descritivo, que se desenvolveu por meio de análise da situação de punção venosa vivenciada por três crianças, após terem sido preparadas com brinquedo terapêutico, cujos dados serão individualmente discutidos. No estudo descritivo o fenômeno é observado e descrito, enquanto o estudo exploratório busca explorar este fenômeno para compreender como ele se manifesta e os fatores a ele relacionados $^{(30)}$.

0 estudo foi realizado na unidade pediátrica de uma instituição hospitalar pública, onde havia a permanência de pais acompanhantes e visitas diárias durante o período da tarde. Em contrapartida, não existia um programa de recreação e nem brinquedos em número suficiente para serem utilizados pelas crianças.

Participaram do estudo três crianças pré-escolares, com idades entre três e seis anos, de ambos os sexos, que foram submetidas à punção venosa; uma de quatro anos de idade, do sexo feminino, e duas de seis anos, sendo uma do sexo masculino e outra do sexo feminino. As crianças eram portadoras de doenças que necessitavam de internação, como asma, broncopneumonia e derrame pleural, anemia falciforme e infecção do trato genitourinário. Os critérios de seleção das crianças para integrarem este estudo foram baseados nos seguintes itens: faixa etária (pré-escolares), condições para brincar, isto é, conscientes, contatuando com o meio ambiente e necessidade de punção venosa. 
A coleta de dados foi feita por uma das autoras, enfermeira especializanda em enfermagem pediátrica. Antes de iniciar o estudo, esta pesquisadora aplicou o brinquedo terapêutico em três crianças, com o objetivo de treinar sua atitude durante a sessão e sua capacidade de realizar observação participante e de descrever 0 comportamento apresentado pelas crianças.

Selecionadas as crianças para o estudo, a enfermeira pesquisadora apresentava-se a seus pais ou responsáveis, a fim de esclarecê-los a respeito do protocolo a ser utilizado e solicitar autorização* para sua aplicação. Informava, ainda, que a criança não seria obrigada a participar da brincadeira, caso não aceitasse.

0 tempo médio utilizado na aplicação do protocolo foi de 40 minutos para a realização de todos os passos, sendo que 15 minutos foram gastos na explanação de uma pequena "história" que lhes foi contada antes do procedimento, 10 minutos na execução da punção venosa e outros 15 minutos na dramatização feita pela criança após a punção.

Para a explicação do procedimento às crianças, foram usados os seguintes brinquedos: 1) Bonecos de pano, caracterizando o pessoal hospitalar, bem como o pai, a mãe, avós, irmãos, empregada e alguns animais domésticos, como cachorro e gato. Tais bonecos mediam $10 \mathrm{~cm}$ de altura, e tinham vestuário que podia ser removido. 2) Material hospitalar normalmente utilizado para punção venosa, como scalpes, equipos, frasco de soro, tala, esparadrapo, bolas de algodão com álcool, seringa, agulhas e garrote. Este material foi utilizado durante a explicação do procedimento à criança e após sua realização, com o objetivo de permitir que ela visualizasse o desenvolvimento de todas as etapas da punção venosa, que manuseasse os objetos utilizados, e que dramatizasse o procedimento nos bonecos, a fim de extravasar seus medos e temores. 0 xérox da fotografia dos brinquedos utilizados encontra-se no Anexo 1.

0 registro do comportamento e das reações apresentadas pela criança, durante a sessão do brinquedo terapêutico, foi feito em uma folha de papel, com local próprio para a identificação e colunas para anotar o tempo, o comportamento da criança e das outras pessoas.

A observação participante permitiu a emergência de dados relativos ao comportamento e à história de vida das crianças, os quais se mostraram importantes para constatar as mudanças de comportamento observadas na criança, com a aplicação do protocolo.

A técnica utilizada para realização da sessão do brinquedo terapêutico encontra-se descrita no modelo de protocolo proposto.

\section{Modelo de protocolo proposto para o preparo da criança para punção venosa com a utilização do brinquedo terapêutico}

Este protocolo foi elaborado segundo alguns critérios selecionados nos guias para preparo de pré-escolares nos procedimentos dolorosos ${ }^{(5,8-9,11,31)}$. Baseou-se também na experiência das autoras, que trabalham com crianças hospitalizadas. Contém os passos a serem seguidos pelo enfermeiro que realizará o preparo da criança para o procedimento, descrevendo as ações a serem seguidas antes, durante e após a realização da punção venosa propriamente dita, assim como as justificativas para as respectivas ações.

\section{ANTES DO PROCEDIMENTO \\ Ação}

1. 0 preparo da criança deve ser realizado preferencialmente por uma enfermeira da unidade, que já tenha estabelecido previamente um relacionamento de confiança com a criança.

2. Inicie o preparo da criança cerca de 30 minutos antes da realização do procedimento.

3. Apresente-se aos pais da criança e converse com eles, orientandoos sobre a necessidade da punção e sobre a utilização do brinquedo terapêutico.

4. Verifique com os pais qual o comportamento da criança frente aos procedimentos dolorosos.
1. A enfermeira é o profissional que convive mais continuamente com a criança; é dela que deve receber apoio no momento dos procedimentos dolorosos ${ }^{(24)}$.

2. Até a idade de sete anos, a fantasia representa um papel no pensamento da criança mais importante do que a realidade objetiva. Se a preparação é feita precocemente, sobra muito tempo para ativar fantasias e medos inconscientes, e se for feita muito em cima da hora, o ego tem pouco tempo para preparar adequadamente suas defesas $^{(8)}$.

3. A maneira como os pais reagem aos procedimentos dolorosos e traumáticos para a criança causa grande impacto no comportamento dos filhos. Se estes percebem que seus pais estão ansiosos, aborrecidos ou inseguros quanto à necessidade do tratamento, seus próprios temores aumentam; se os pais demonstrarem convicção, isto também é percebido pela criança. Conversar com os pais promove o conhecimento, facilitando a aceitação do procedimento por eles e pela criança $^{(31)}$.

4. Estes dados subsidiam 0 conhecimento do enfermeiro a respeito da provável reação da criança, favorecendo, conforme indicam $^{(11)}$, a individualização do cuidado prestado.

\footnotetext{
* A autorização dos pais foi feita verbalmente, conforme as normas institucionais vigentes na época da coleta dos dados, que antecedeu à resolução 196/ 96, que exige autorização assinada num termo de consentimento
} 
5. Realize uma sessão individual de 5. 0 tempo de duração de uma brinquedo terapêutico, que deverá sessão de brinquedo terapêutico durar cerca de 15 minutos, conforme deve ser de 15 a 45 minutos $^{(21)}$. descrito nos itens seguintes.

6. Convide a criança para brincar, permitindo que ela escolha o local de sua preferência: sala de brinquedos do hospital, seu próprio leito, ou qualquer outra área conveniente.

7. Informe sobre o tempo de duração da brincadeira e que após o seu término os brinquedos serão recolhidos.

8. Apresente os brinquedos à criança e permita que ela os manuseie.

9. Conte uma história à criança envolvendo os brinquedos, para explicar a punção venosa, permitindo que dramatize nos bonecos 0 procedimento. 0 módulo da história que foi contada está no Anexo 2.

10. Enquanto conta a história realize a dramatização do procedimento nos bonecos, expondo à criança o que ela irá sentir e o que pode fazer para ajudar, por exemplo: deitar-se, permanecer com o membro imóvel, chorar se sentir vontade.

11. Oriente a criança quanto a necessidade de restringir os movimentos e que será permitido que chore e expresse seus pensamentos de dor, desconforto, raiva etc...

12. Informe a função de cada material instalado no boneco (equipo, scalpe, esparadrapo, soro etc...).

13. Durante a sessão, utilize palavras adequadas, no nível do desenvolvimento da criança.
6. A escolha do local pela própria criança a deixará mais a vontade "hospitalar"(24).

7. A colocação desses limites é importante para que a criança não queira brincar indefinidamente, ou ficar com os brinquedos, porque estes têm objetivos definidos ${ }^{(12)}$.

8. Observar e manusear os brinquedos ajudará a criança a familiarizar-se com eles e, conseqüentemente, com o material hospitalar, diminuindo o medo que estes possam representar, além de estimular a elaboração de histórias e/ou fantasias. Essa experiência direta confronta a criança com a sua realidade, dando-Ihe oportunidade de fazer perguntas sobre ela ou sobre os materiais ${ }^{(9)}$. 9. A história é considerada ${ }^{(32)}$ como um meio natural e espontâneo para informar à criança sobre sua realidade. 0 brinquedo terapêutico é um meio efetivo de lidar com fantasias e medos, principalmente aqueles associados a procedimentos intrusivos e/ou dolorosos; visualizar e manusear o equipamento ajudará a criança a aprender $e$ isto promove cooperação( $0^{(11)}$.

10. Nesta idade a criança permanece egocêntrica e tem 0 pensamento concreto, mas também pode entender explicações simples e direções a seguir ${ }^{(11)}$.

11. A criança perceberá que seus sentimentos são aceitos e que segurá-la é uma medida para protegê-la ${ }^{(31)}$.

12. Explicar a função de cada material utilizado facilitará a compreensão sobre 0 procedimento ${ }^{(31)}$.

13. 0 vocabulário da criança préescolar ainda é restrito e pode acontecer que ela interprete mal as palavras com fonética por não provocar grandes alterações em seu meio ambiente

14. Responda as perguntas feitas pela criança.

15. Fale com a criança que a punção venosa nunca é usada como punição e dê-lhe uma explicação simples e honesta.

16. Reserve um tempo para conversar com a criança e para deixá-la fazer perguntas.

\section{DURANTE 0 PROCEDIMENTO}

semelhante ou se assuste desnecessariamente quando são empregadas palavras não familiares ${ }^{(5)}$.

14. Para que ela tenha o controle sobre a situação do brinquedo ${ }^{(12)}$. 15. 0 pré-escolar está desenvolvendo sua consciência e pode ver a punção venosa como uma punição para suas ações, mas pode entender a necessidade real da injeção, através de uma explicação simples ${ }^{(31)}$.

16. Para que possa tirar dúvidas a respeito dos procedimentos ${ }^{(12)}$.
17. Incentive a participação dos pais durante o procedimento, orientando-os para que segurem a mão da criança, conversem e fiquem numa posição que possam ser vistos.

18. Permita ao pré-escolar escolher em qual local ele quer que seja feita a punção venosa, encorajando 0 desenvolvimento de sua capacidade de ter iniciativa.

19. Coloque um esparadrapo ou "band-aid" no local da realização da punção venosa.
17. Os pais são uma fonte de apoio tranqüilizadora para a criança e, nesta idade, ainda há grande ansiedade pela separação ${ }^{(31)}$.

18. Nesta idade a criança procura dominar as situações e tem prazer em suas realizações. Decidir está de acordo com a característica da idade na qual está desenvolvendo iniciativa $^{(3)}$.

19. Nesta idade a criança não tem noção das fronteiras corpóreas, isto faz com que tema a perda de conteúdo corpóreo ${ }^{(2)}$.

\section{APÓS O PROCEDIMENTO}

20. Elogie os comportamentos da criança que facilitaram a realização do procedimento.

21. Forneça novamente os brinquedos anteriormente utilizados para que a criança brinque, dramatizando o procedimento, inclusive com o equipamento real, sob supervisão.

22. Anote e analise o conteúdo da dramatização da criança e como se comportou durante a punção venosa.

20. A criança pré-escolar sente prazer em suas realizações ${ }^{(31)}$.

21. Dramatizar proporciona à criança uma maneira de descarregar tensões e medos ${ }^{(33)}$.

22. Isto permite verificar a influência da utilização do brinquedo sobre 0 comportamento da criança ${ }^{(31)}$ e favorece o conhecimento de suas necessidades $^{(21)}$.

\section{RESULTADOS E COMENTÁRIOS}

A intervenção realizada com cada criança submetida à sessão do brinquedo terapêutico para preparo da punção venosa será discutida individualmente, expressando a nossa compreensão sobre sua evolução. 
CASO 1: Nome: A.A.G.O.R. Sexo: Feminino Idade: quatro anos Diagnóstico: Crise asmática

Chegou à unidade pediátrica encaminhada do Pronto Socorro, acompanhada pela avó. Encontrava-se muito quieta, pouco comunicativa e recebia soroterapia. Segundo a avó, a mãe da criança deixou-a sob seus cuidados há três meses e a partir dessa data já havia sido hospitalizada três vezes em diferentes hospitais, sempre com o mesmo problema de saúde. Esta era a sua quarta internação. Nas anteriores, de acordo com os dados colhidos, apresentava-se chorosa, agitada, agressiva e sem conseguir dormir, tendo sido necessário o acompanhamento de uma psicóloga. A avó informou também que durante a realização da punção venosa, no Pronto Socorro, ela mostrou-se muito chorosa e agitada, sendo necessárias duas pessoas para segurá-la.

No segundo dia de sua internação na unidade pediátrica, surgiu a necessidade de nova punção venosa. Conversamos com a avó sobre o procedimento e o uso do brinquedo para explicar à criança a técnica da punção venosa e o porquê de sua realização. Convidamos a menina para brincar, o que aceitou imediatamente. Durante a sessão do brinquedo terapêutico, pudemos observar que ela prestava muita atenção nas explicações oferecidas por meio da demonstração nos bonecos. Após a explicação, manipulou os brinquedos e o material hospitalar com grande interesse, dramatizando a técnica no boneco pai.

No momento da realização da punção, a criança chorou mas manteve-se calma, pediu para ficar sentada com o braço estendido, não permitindo que a segurassem; depois informou não haver doído muito. É importante relatar que a avó permaneceu na sala e permitiu-se que a criança escolhesse o local da punção e a posição que gostaria de ficar na maca.

Terminado o procedimento, oferecemos-lhe os materiais de dramatização para brincar. Ela aceitou imediatamente, solicitando que a avó saísse da sala. Inicialmente manipulou os brinquedos, depois introduziu repetidamente o scalpe nos bonecos pai e mãe e a seguir passou a puncionar o braço da boneca menina, deitandoa sobre uma fralda e tendo a boneca avó sentada a seu lado e a boneca mãe distante. Também puncionou o braço do boneco menino, colocando-o deitado, com a boneca mãe sentada longe dele durante algum tempo, para depois sentar a boneca mãe ao lado do boneco menino. No final, retirou o scalpe do boneco menino e entregou-nos todo o material, dizendo que queria assistir televisão.

Vale ressaltar que terminando a sessão conversamos com a avó da criança que nos revelou que A. G. 0. R. possui um irmão menor que ficou morando com a mãe e que o pai encontrava-se internado por alcoolismo. Revelou também que nenhuma notícia havia sido dada às duas crianças sobre a separação de sua família.

Analisando o comportamento desta criança durante a sessão, observamos o quanto foi significativa a escolha dos bonecos "pai" e "mãe" para serem puncionados (não seriam eles que deveriam ser castigados?!).

Quando puncionou os braços da "menina" (ela é esta menina) colocou a avó ao seu lado, como figura representativa do afeto que dela recebe, ao passo que colocou os bonecos "pai" e "mãe" afastados, simbolizando o distanciamento entre eles. Pudemos também compreender a posição do boneco menino ao lado da "mãe", pois não é com a mãe que o irmãozinho está vivendo?! (apesar de, no primeiro momento, a mãe ter sido afastada, demonstrando que a assistência e o carinho estão centrados na figura da avó). A partir desse fato, a intervenção da enfermagem foi encaminhá-la à psicóloga da instituição para acompanhamento.

No terceiro dia de hospitalização foi necessária uma nova punção. Durante este procedimento, quando não foi utilizado novamente o protocolo de preparo, apesar de ter chorado muito, a criança manteve-se quieta, receptiva e não demonstrou agressividade; também não foi preciso segurá-la. Considerando o comportamento apresentado por ela durante as punções anteriormente realizadas no Pronto Socorro e em outras internações, acreditamos que houve um efeito positivo do uso do brinquedo no preparo para a punção venosa.

Outro aspecto marcante no transcorrer da internação foi a mudança que se operou no relacionamento da criança com os funcionários e com as demais crianças internadas na unidade. Antes da intervenção com o brinquedo, era quieta e pouco comunicativa. Após a sessão, passou a conversar e a brincar com as demais crianças e com a equipe de enfermagem ${ }^{(12)}$, que constatou mudanças positivas no comportamento de crianças hospitalizadas submetidas a uma sessão de Brinquedo Terapêutico, com aumento significativo de "comportamentos com interação social, iniciados pelas crianças". Essa procura de integração com outras pessoas ${ }^{(34)}$, é uma característica de criança de ego fortalecido. Uma das funções do brinquedo é favorecer a socialização da criança ${ }^{(14)}$. Este fato é apoiado por Aberastury ${ }^{(35)}$, quando declara: "Ao brincar, a criança desloca para o exterior seus medos, angústias e problemas internos, dominando-os por meio da ação. Repete no brinquedo todas as situações excessivas para seu ego fraco e isto lhe permite, devido ao domínio sobre os objetos externos a seu alcance, tornar ativo aquilo que sofreu passivamente, modificar um final que lhe foi penoso, tolerar papéis e situações que seriam proibidas na vida real tanto 
interna como externamente e também repetir à vontade situações prazerosas"(35).

CASO 2 Nome: S.A.G.S. Sexo: Feminino Idade: seis anos Diagnóstico: Anemia falciforme e infecção do trato genitourinário.

Foi admitida na unidade, acompanhada pela mãe. Esta referiu que a criança já havia sido hospitalizada anteriormente devido à anemia falciforme e sempre se mostrou calma e comunicativa com todos os funcionários do hospital; informou também que ao ser submetida à punção venosa, chorava muito e após ficava nervosa.

Durante os primeiros dias da atual internação, enquanto não houve necessidade da punção, ficou calma, comunicativa e gostava de acompanhar a equipe de enfermagem na realização de suas atividades, além de se mostrar muito carinhosa com toda a equipe de saúde.

No terceiro dia de internação, com o início da antibioticoterapia por via endovenosa, foi preciso submetê-la à punção venosa. Quando informada da necessidade desse procedimento, tornou-se muito chorosa e agitada, não querendo falar com ninguém. A enfermeira responsável pela aplicação do protocolo conversou com a mãe sobre a punção e a utilização do brinquedo para explicar o procedimento. Ao convidá-la para brincar, aceitou imediatamente, solicitando que a mãe ficasse junto dela. Durante a orientação demonstrada no boneco, ficou atenta à explanação e logo após pediu para brincar com o material, manuseando principalmente a seringa e a agulha.

No momento de se proceder a punção propriamente dita, a criança chorou dizendo que iria doer e perguntando quanto tempo precisaria ficar com "aquilo". Sendo-lhe devolvida a pergunta feita, ela mesma referiu ser necessário ficar com o remédio até acabar. Um dos eventos mais aterrorizantes para a criança é a injeção, procedimento percebido como intrusivo, hostil e mutilador, que poderá durar indefinidamente ${ }^{(36)}$. Apesar disso a criança permitiu a punção, sem ser necessário que alguém a segurasse e depois verbalizou não haver doído muito. Terminada a punção, solicitou para brincar novamente com o material, pedindo à mãe para sair da sala. Durante sua dramatização nos bonecos, demonstrou interesse pelo material da punção, introduzindo o scalpe no boneco que referiu ser seu irmão, passando a realizar todos os passos do procedimento corretamente, verbalizando-os e conversando com o boneco.

No quarto dia de internação, foi necessária outra punção; chorou muito, solicitando a permanência de sua mãe na sala, mas não foi preciso segurá-la.

Analisando o comportamento de S.A.G.S. após a sessão, pudemos constatar que ela havia conseguido entender a necessidade da punção e também a técnica, como ficou evidenciado pela demonstração que realizou no boneco. 0 brinquedo terapêutico é um meio da criança lidar com fantasias e medos, e quando se permite que visualize e manuseie os instrumentos, ela começa a entender melhor o procedimento, passando geralmente a cooperar ${ }^{(11)}$.

0 jogo permite ao ego assimilar toda a realidade, ou seja, integrá-la para revivê-la, dominá-la ou compensá-la ${ }^{(37)}$. Assim, quando as crianças dramatizam ações desagradáveis, reduzem parte do desprazer e tornam as situações mais toleráveis.

CASO 3 Nome: E.C.A. Sexo: Masculino Idade: seis anos Diagnóstico: Broncopneumonia e derrame pleural.

Chegou à unidade pediátrica, transferido de outro hospital, acompanhado pela mãe. Encontrava-se choroso, agitado, referindo dor no peito e não permitia aproximação das equipes de enfermagem e médica. A mãe informou que a criança era portadora de dislalia, que piorou significativamente com a internação, tornando-se também nervosa, agitada e agressiva. É importante relatar que antes da sua admissão na unidade, ainda no Pronto Socorro, ao ser realizada a punção venosa, foram necessárias seis pessoas para segurá-lo.

Nos dois dias seguintes à internação, não permitia a aproximação de nenhuma pessoa, exceto de sua mãe; mesmo no horário de visita, permanecia quieto e não conversava com seu pai nem com sua avó. Com a convivência diária e dialogando com ele, passou a ficar mais calmo aceitando a nossa presença, mas não respondia ainda as perguntas que the eram feitas.

No quarto dia de internação, foi necessária nova punção venosa. Conversamos com sua mãe sobre o brinquedo terapêutico e sua finalidade e ele foi convidado a brincar. Aceitou imediatamente, o que nos surpreendeu, pois esperávamos resistência de sua parte. Durante a explicação da técnica, através da dramatização no boneco, ouviu atentamente e manipulou os materiais, entregando-os de volta após puncionar o braço da boneca menina, verbalizando que sairia sangue.

No momento da punção, chorou e pediu à mãe para ficar junto dele, permitindo que o procedimento fosse executado sem ser preciso segurá-lo. Este comportamento surpreendeu a mãe, que verbalizou não esperar que ficasse quieto. 0 mesmo aconteceu com os funcionários, que ofereceram ajuda para segurá-lo, pois não acreditavam que ele permitisse a punção.

Após o procedimento, ele pegou os bonecos e ficou durante algum tempo observando-os; a seguir, perfurou várias vezes os olhos e a boca da boneca enfermeira com o scalpe, dizendo que iria furar-lhe os olhos.

Esse comportamento parece demonstrar o trauma vivenciado pela criança com a internação e sua mágoa relacionada aos profissionais de saúde que haviam lidado com ele, em especial a equipe de enfermagem, pois demonstrou em seu brinquedo uma violência acentuada contra a boneca enfermeira. Após essa "descarga emocional", o menino tornou-se mais calmo e cooperativo, 
passando a relacionar-se melhor com a equipe de enfermagem e com as outras crianças da enfermaria.

Autores $^{(3,16,38)}$ referem que infligindo aos bonecos os processos que sofreu como sujeito passivo, a criança começa a entender que não precisa ser sempre vítima desamparada, mas pode fazer aos outros o que the foi feito. Desta forma, pela brincadeira, o sofrimento passivo torna-se um domínio ativo e os acontecimentos traumáticos, em particular a hospitalização e todas as suas facetas podem ser melhor dominados.

Nas brincadeiras as crianças dão vazão ao ódio e à agressão que estão sentindo, expondo esses sentimentos para um meio conhecido, sem que haja um retorno do ódio e da violência desse meio para elas ${ }^{(38)}$. 0 autor continua referindo que se deve aceitar a agressividade na brincadeira, pois a criança sente-se desonesta se necessitar esconder o que estiver sentindo. As crianças brincam por prazer, mas também para dominar angústias e controlar idéias ou impulsos que as estão sufocando.

Com o transcorrer da hospitalização, foram necessárias outras punções, durante as quais se mostrava choroso, porém não foi necessário segurá-lo. Passou a conversar com as pessoas e também com seu pai e avó; a mostrar uma expressão facial mais alegre e solicitava para brincar com maior freqüência. Tal comportamento ${ }^{(34)}$, é compatível com o apresentado por crianças que têm um ganho no fortalecimento de seu ego.

\section{CONSIDERAÇÕES FINAIS}

0 resultado do preparo das crianças para punção venosa, com utilização do brinquedo terapêutico, foi positivo, uma vez que elas:

- tornaram-se mais cooperativas, não necessitando restringi-las, como ocorrera em punções anteriores, o que parece demonstrar que houve diminuição do medo relacionado ao procedimento; - demonstraram ter compreendido a necessidade e a técnica da punção venosa, uma vez que a dramatizaram adequadamente nos bonecos;

- tiveram oportunidade de exteriorizar seus sentimentos de mágoa e revolta contra os procedimentos intrusivos e contra os profissionais que os realizaram, conforme a criança E.A.C. tão bem dramatizou, introduzindo a agulha nos olhos e na boca da boneca enfermeira; - tiveram oportunidade de elaborar situações familiares traumáticas, o que foi bem ilustrado pela criança A.A.G.O.R que dramatizou a separação de sua mãe;

- passaram a se relacionar melhor com as outras crianças e a equipe de enfermagem, especialmente conosco, mesmo que a punção venosa tenha sido executada por nós. Inclusive passaram a nos procurar com freqüência, solicitando, muitas vezes, para brincar novamente. Este fato é também descrito nos trabalhos ${ }^{(6,12,27)}$, onde ficou demonstrado o início do relacionamento com a criança.

Outro aspecto que consideramos importante comentar, embora não se refira diretamente à criança, foi a mudança ocorrida no comportamento dos funcionários de enfermagem do setor em que a coleta de dados foi realizada. Antes da aplicação do protocolo, eles verbalizaram descrença em relação ao efeito do brinquedo terapêutico; depois de sua realização, mostraram-se surpresos com os efeitos observados, passando a demonstrar interesse e a sugerir sua aplicação junto às crianças que tinham necessidade de punção venosa e apresentavam-se agitadas, chorosas e agressivas. Por solicitação da enfermeira do centro cirúrgico da instituição, surgiu também a possibilidade de estender a utilização do brinquedo terapêutico no preparo para a cirurgia.

Em relação ao tempo gasto para o preparo inicial, cerca de 15 minutos, incluindo a narração da história com demonstração da punção e manuseio dos objetos pela criança, acreditamos que não deve ser empecilho à sua utilização, tendo em vista os benefícios gerados para a criança; vale ressaltar a redução do desgaste físico e emocional não só da criança, mas também da equipe, considerando-se não ser necessário um maior número de recursos humanos para conter a criança na hora da punção. Além do mais, sabemos por experiência profissional, que o período gasto na execução da punção venosa em uma criança sem preparo prévio é igual ou superior, havendo ainda o agravante de dificultar o tratamento e interferir no seu desenvolvimento normal.

Pelo exposto, acreditamos que os objetivos traçados foram alcançados, pois o protocolo proposto para o preparo da criança para punção venosa, com utilização do brinquedo terapêutico, foi realizado com êxito, foi de fácil aplicação e mostrou-se eficaz para amenizar o estresse gerado em função desse procedimento. Assim, a nosso ver, é um recurso indispensável que deve integrar o plano de assistência de enfermagem nos hospitais e setores pediátricos.

Sugere-se que a enfermeira incorpore o brinquedo na sua prática diária, pois ele pode ser usado em todos os níveis do processo de enfermagem (avaliação, diagnóstico e intervenção), em resposta aos problemas psicossociais do paciente ${ }^{(39)}$. Uma forma de assegurar que a brincadeira faça parte dos cuidados de enfermagem todos os dias, seria incorporá-lo ao plano de cuidado com a criança hospitalizada ${ }^{(25)}$.

Assim sendo, sugerimos que nas escolas de enfermagem e nas instituições de saúde seja enfatizado o brincar como uma necessidade da criança, bem como sejam levadas em consideração as características de seu desenvolvimento. As crianças têm direito a brincar, pois a brincadeira faz parte de suas vidas; privá-las disso é privá-las da oportunidade de crescer e se desenvolver com saúde. 
ANEXO 1

\section{Xérox da foto dos brinquedos usados na sessão de brinquedo terapêutico}

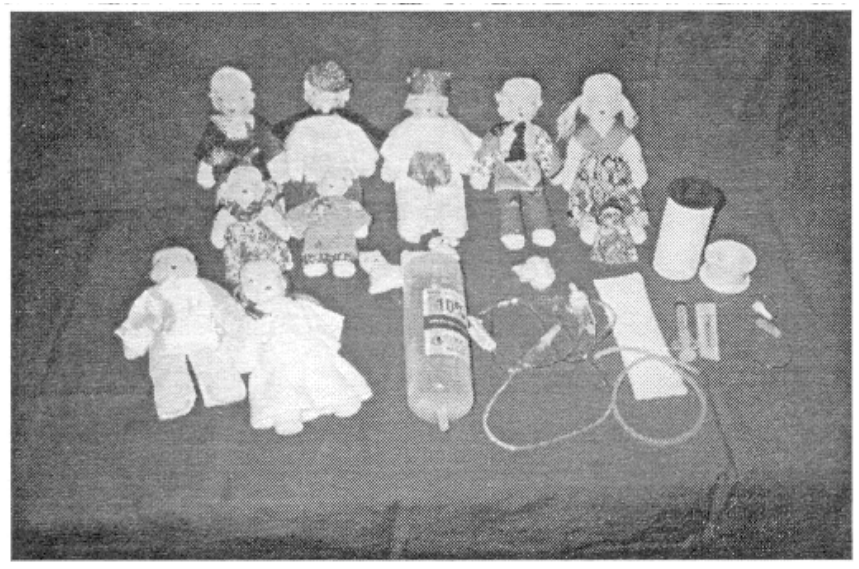

ANEXO 2

História utilizada para explicar e dramatizar a punção venosa durante a sessão do brinquedo terapêutico

Um dia Mariazinha acordou cedo em sua casa e sua mãe viu que ela estava com febre e dor de garganta. Então levou-a ao médico, que

\section{REFERÊNCIAS BIBLIOGRÁFICAS}

1. Bowly J. Cuidados maternos e saúde mental. São Paulo: Martins Fontes; 1981.

2. Whaley LF, Wong DL. Enfermagem pediátrica. $2^{\mathrm{a}}$ ed. Rio de Janeiro: Guanabara; 1989.

3. Erikson EH. Infância e sociedade. $2^{\mathrm{a}}$ ed. Rio de Janeiro: Zahar; 1976.

4. Velloso NA. A influência da assistência de enfermagem no ajustamento ao hospital, de crianças admitidas na véspera ou no dia da operação. Rev Esc Enfermagem USP 1973; 7(1): 14-5.

5. Ritchie JA. Preparation of toddler and preschool children for hospital procedures. Can Nurs 1979; 75(11): 30-2.

6. Angelo M. Brinquedo: um caminho para a compreensão da criança hospitalizada. Rev Esc Enfermagem USP 1985; 19(3): 213-23.

7. Barton PH. The relationship between fantasy ant overt street reaction on children to hospitalization. [doctor]. Flórida (US): University of Flórida; 1964.

8. Wu R. Explaining treatments to young children. Am J Nurs 1965; 65(7): 71-3.

9. Eckhardt L, Prugh D. Preparing children psychologically for parinful medical and surgical procedures mimeografado.

10. Waechter EH, Blake FG. Enfermagem pediátrica. Rio de Janeiro: Interamericana; 1979.

11. Evans ML, Hansen BD. Administering injections to different agedchildren. MCN 1981; 6: 194-6. a examinou e disse que ela precisava ficar internada para tomar remédio, porque estava doente. Mariazinha então foi levada pela mãe ao hospital para ser internada, onde ficou junto dela. Quando a enfermeira foi conversar com Mariazinha ela chorou muito falando que estava com medo.

A enfermeira então disse à Mariazinha que iria colocar uma agulha em seu braço para ela tomar remédio, que iria doer um pouquinho, mas que depois a dor passaria. Colocou a Mariazinha deitada e disse-lhe que ficasse quietinha e não mexesse o braço, porque a agulha poderia machucá-la, advertindo-a que se não ficasse quieta, outra pessoa iria segurá-la e isso não seria agradável.

A enfermeira preparou o remédio, pegou a borrachinha* e colocou-a apertado no braço da Mariazinha para ver se ela possuia uma veia boa para aplicar o remédio; depois segurou firme o braço dela, passou o algodão e com a agulha furou o seu braço, soltou a borrachinha e colocou a mangueirinha* na agulha abrindo a rodinha* para que o remédio entrasse em seu corpo. Depois pegou o esparadrapo e colocou sobre a agulha para esta não sair do lugar. Pegou uma tabuinha de por na mão* e colocou sob seu braço prendendo com esparadrapo, para evitar Mariazinha se mexer e a agulhar sair. Mariazinha tomou o remédio todo dia, então a enfermeira retirou a agulha. Quando sarou, ela pôde ir embora para casa com sua mãe.

* Termos utilizados pelas crianças para descreverem o material hospitalar

12. Ribeiro CA. 0 efeito da utilização do brinquedo terapêutico, pela enfermeira pediatra, sobre o comportamento de criança recémhospitalizadas. [dissertação]. São Paulo (SP): Escola de Enfermagem/USP; 1986.

13. Marlow DR, Redding BA. Enfermeria pediatrica, el pré-escolar, el escolar, pubertad y adolescência. $6^{a}$ ed. Buenos Aires: Panamericana; 1991. v. 3.

14. Trezza, EMC. Função dos jogos e brinquedos na vida da criança. J Pediatria 1977; 42(6): 55-8.

15. Jersild AT. Psicologia da criança. $2^{\mathrm{a}}$ ed. Brasília: Itatiaia; 1973. 16. Bettelheim B. Uma vida para seu filho, pais bons o bastante. $24^{\mathrm{a}}$ ed. Rio de Janeiro: Campus; 1988.

17. Geets C. Melanie Klein. São Paulo: EDUSP; 1977.

18. Lebovici S, Diatkine R. Significado e função do brinquedo na criança. Porto Alegre: Artes Médicas; 1985.

19. Erickson F. Reaction of children to hospital experience. Nurs Outlook 1958; 6(9): 501.

20. Machado DVM. 0 brinquedo e suas funções. Anais Nestl 1977; 54-8.

21. Green CS. Undestanding children's needs through therapeutic play. Nurs Horshan 1974; 4(10): 31-2.

22. Barton PH. Nursing assessment and intervention though play. In: Bergensen BS. et al. Current concepts us clinical nursing. Saint Louis: Mosby; 1969. p. 203-7.

23. Clatworth SM. The effect of terapeutic play on the anxiety behavions of hospitalized children. [doctor]. Boston (US): School of Education/Boston University; 1978. 
24. Petrillo M, Sanger S. Cuidado emocional del niño hospitalizado. México: Prensa Médica; 1972.

25. L'evieux-Anglin L, Sawyer E. Incorporating play interventions into nursing care. Pediatr Nurs 1993; 19(5): 459-63.

26. Moraes E. Manifestações de tensão e comportamento de adaptação de crianças hospitalizadas. Rev Esc Enfermagem USP 1971; 5(1): 44-57.

27. Martins DMR. et al. Assistência de enfermagem a crianças hospitalizadas quando enfrentam situações desagradáveis- parte I. Rev Esc Enfermagem USP 1979; 13(2): 157-69.

28. Ribeiro CA. Sentindo o valor das experiências significativas para a aprendizagem: relato de duas situações vividas com crianças hospitalizadas. Rev Esc Enfermagem USP 1983; 17(3): 179-203.

29. Duarte ERM et al. A utilização do brinquedo na sala de recuperação: um recurso a mais para assistência de enfermagem à criança. Rev Bras Enfermagem 1987; 40(1): 74-81.

30. Polit DF, Hungler RP. Fundamentos da pesquisa em enfermagem. $3^{\text {a }}$ ed. Porto Alegre: Artes Médicas; 1995.

31. Martins DMR, Ribeiro CA. Assistência de enfermagem às crianças hospitalizadas quando enfrentam experiências difíceis e/ou desagradáveis; 1986. mimeografado.
32. Moraes $\mathrm{E}$ et al. Estudantes de enfermagem assistem crianças doentes utilizando "entrevista com brincadeira". Rev Esc Enfermagem USP 1979; 13(1): 29-39.

33. Winnicott DW. A criança e o seu mundo. $6^{\text {a }}$ ed. Rio de Janeiro: Zahar; 1985.

34. Denyes MJ. A child with hirchsprung's disease uses a nurse to gaur ego streught. In: American Nurses Association. Ana clinical sessions. New York: Appleton - Century - Crofts; 1968. p.155-61. 35. Aberastury A. A criança e seus jogos. Porto Alegre: Artes Médicas; 1992.

36. Angelo M. Hospitalização: uma experiência ameaçadora In: Steiner MH F. Quando a criança não tem vez: violência e desamor. São Paulo: Pioneira; 1988. p. 101-8.

37. Pulaski MAS. Compreendendo Piaget: uma introdução ao desenvolvimento cognitivo da criança. Rio de Janeiro: Guanabara; 1986.

38. Winnicott DW. 0 brincar e a realidade. Rio de Janeiro: Imago; 1975.

39. Walker C. Lise of art anal play therapy in pediatric oncology. J Pediatr Oncol Nurs 1984; 6(4): 121-6. 